Article

\title{
Examining the Impact of Greenspace Patterns on Land Surface Temperature by Coupling LiDAR Data with a CFD Model
}

\section{Weizhong Su ${ }^{1, *}$, Yong Zhang ${ }^{2, \dagger}$, Yingbao Yang ${ }^{2, \dagger}$ and Gaobin Ye ${ }^{1,3}$}

1 State Key Laboratory of Lake Science and Environment, Nanjing Institute of Geography and Limnology, Chinese Academy of Sciences, No. 73 East Beijing Road, Nanjing 210008, China; E-Mail: xiegb0000@163.com

2 School of Earth Sciences and Engineering, Hohai University, No. 1 Xikang Road, Nanjing 210098, China; E-Mails: hhuzhangyong@163.com (Y.Z.); yyb@hhu.edu.cn (Y.Y.)

3 University of Chinese Academy of Sciences, No. 19A Yuquan Road, Beijing 100049, China

$\dagger$ These authors contributed equally to this work.

* Author to whom correspondence should be addressed; E-Mail: wzsu@niglas.ac.cn or su_wz@hotmail.com; Tel.: +86-25-8688-2132; Fax:+86-25-5771-4759.

External Editor: Shangyi Zhou

Received: 10 July 2014; in revised form: 18 September 2014 / Accepted: 22 September 2014 / Published: 30 September 2014

Abstract: Understanding the link between greenspace patterns and land surface temperature is very important for mitigating the urban heat island (UHI) effect and is also useful for planners and decision-makers for providing a sustainable design for urban greenspace. Although coupling remote sensing data with a computational fluid dynamics (CFD) model has widely been used to examine interactions between UHI and greenspace patterns, the paper aims to examine the impact of five theoretical models of greenspace patterns on land surface temperature based on the improvement of the accuracy of CFD modeling by the combination of LiDAR data with remote sensing images to build a $3 \mathrm{D}$ urban model. The simulated results demonstrated that the zonal pattern always had the obvious cooling effects when there are no large buildings or terrain obstacles. For ambient environments, the building or terrain obstacles and the type of greenspace have the hugest influence on mitigating the UHI, but the greenspace area behaves as having the least cooling effect. A dotted greenspace pattern shows the best cooling effect in the central area or residential district within a city, while a radial and a wedge pattern may result in a "cold source" for the urban thermal environment. 
Keywords: greenspace patterns; land surface temperature; urban heat island (UHI); computational fluid dynamics (CFD) model; LiDAR data

\section{Introduction}

The impacts of urbanization on local climate are well documented [1]. One of the most relevant impacts is the urban heat island (UHI) effect, which has become a highly interesting focus for scientists, planners and engineers, due to its adverse environmental and economic impacts [2]. In response to predictions of increasingly frequent heat waves, an adaptation strategy has been suggested to pay more attention to the planning, design and installation of urban greenspace [3-6], such as parks [7,8], green roofs [9] and trees along streets [10-12]. UHI can be mitigated mainly by balancing the relative amounts of various types of greenspace in present research and practical planning.

However, available land for increasing greenspaces is usually very limited for a heavily-urbanized city [13]. The mitigation of UHI cause more attention to be paid to the optimization of greenspace spatial patterns, and also, much research has been conducted to examine the amount, composition (the abundance and variety of green land types) and configuration (spatial arrangement) of greenspace based on the land patches and landscape metrics from the landscape ecology method [14-16]. However, little research has explored the effects of theoretical spatial patterns of greenspace on land surface temperature. Moreover, the ambient environment of the greenspace, such as greenspace type, surface characteristics and greenspace areas, may bias the estimation of the cooling effect of the greenspace pattern [17-19]. An effective design mechanism to mitigate the UHI relies on understanding the information about the comprehensive effect of the ambient environment and spatial patterns of greenspace on land surface temperature.

The present approaches [20] that understand and qualify how the urban greenspace affects the land surface temperature distribution include field measurement [21,22], thermal remote sensing [23], small-scale climate modeling [24,25] and the CFD model [26-28]. Thermal remote sensing is a useful technique to estimate spatial distributions of land surface temperature [29], but lacks the ability to provide information on the causes of the formation of spatial distributions and to predict the change of land surface temperature. CFD modeling can not only determine the spatial distribution of land surface temperature, but also can provide information on the interaction mechanisms forming the temperature distribution [30]. The ENVI-met (V3.1 Beta V), as one of the CFD models, was developed by the Research Group Climatology at Ruhr University Bochum in Germany [31] and has been widely applied in urban climate studies. Some studies have proven that the ENVI-met model could simulate the interactions between surface, plants and the atmosphere within the urban environment [32] and showed that greenspace could help to improve human thermal comfort by reducing air temperature and reflected radiation [33]. Although ENVI-met has appeared more appropriate for urban planning, being able to take into account the effect of buildings' geometry and vegetation on the flow pattern and temperature distribution, a better tuning of the model is needed to properly predict the heat fluxes and the air temperature at the neighborhood scale [34]. Regulating simulation time, atmospheric parameters and surface characteristics can improve the simulation accuracy of the ENVI-met model [10,34]. 
However, how the 3D model of surface features in ENVI-met affects the simulation accuracy has not been considered in the model. Much research has mainly adopted the 2D or simplified 3D model, which were acquired by GIS data and a land cover map. This means that an accurate 3D model of urban space should be expected to improve the accuracy of the CFD model. LiDAR (light detection and ranging) as an active and 3D remote sensing technology can obtain the plain metric and vertical positions and provide a unique and promising solution to extract urban $3 \mathrm{D}$ information $[35,36]$.

The paper mainly aims to (1) study how five theoretical patterns of greenspace affect land surface temperature based on the validated CFD model by field survey and the 3D urban model; (2) explicate the comprehensive effect of spatial patterns of greenspace and their ambient environment on land surface temperature to provide decision makers and planners with guidance on land use and UHI mitigation.

\section{Methods and Data}

The ENVI-met model as the CFD model is adopted to examine the impact of greenspace patterns on land surface temperature. It employs the non-hydrostatic incompressible Navier-Stokes equations for the wind field, the k-epsilon turbulence model and a combined advection-diffusion equation with the alternating directly implicit (ADI) solution technique [31] to simulate the interaction between microclimate and urban surfaces, such as walls, soil and vegetation. This model requires two main input files, including the configuration file containing settings for initialization values and timings and the 3D model file designing the spatial location, height of buildings, vegetation and soils based on a cell in the simulated area. The four steps are described below:

(1) Constructing a 3D model of the study area based on LiDAR data and IKONOS images;

(2) Initializing the CFD model by field survey and defining basic settings, including temperature at $1.5 \mathrm{~m}$ above ground: $299 \mathrm{~K}$; wind speed (at $10 \mathrm{~m}$ above ground): $1.6 \mathrm{~m} / \mathrm{s}$; wind direction: south to north; RH: $84 \%$; roughness length in $10 \mathrm{~m}$ : 0.1 ; total simulation: $24 \mathrm{~h}$;

(3) Calibrating the CFD model: comparing simulated temperature with measured temperature and adjusting the inputted parameters to make the simulation stable and the errors reduce;

(4) Outputting the simulated temperature: simulating the temperatures of different scenarios based on systematic verification and reliability analysis of the ENVI-met model after inputting the two main files (Figure 1).

\subsection{The Study Area and Data to Calibrate the CFD Model}

The Jiangning campus of HoHai University is selected as an experiment area to calibrate ENVI-met by field survey to confirm its suitability, which is located in the southwest of Nanjing city $\left(31^{\circ} 14^{\prime}-32^{\circ} 17^{\prime} \mathrm{N}, 118^{\circ} 21^{\prime}-119^{\circ} 14^{\prime} \mathrm{E}\right)$, Jiangsu province, China (Figure 2) [37]. The simulated area (with the red-line box in Figure 2a) is determined mainly to consider several types of land cover, such as vegetation (grass, trees along the road and trees located on the mountain), road, building and public squares.

For CFD simulation, the heights of buildings and trees must be obtained based on the reconstruction of the $3 \mathrm{D}$ model. Airborne topographic LiDAR is the most popular data to extract the terrain and 
building information [38-40]. Present airborne LiDAR data can have submeter resolution and centimeter position accuracy. These properties are superior to almost all other remote sensing datum and, therefore, greatly extend the capabilities and potentials of urban remote sensing. The airborne LiDAR data, which was acquired on 4 November 2010, on aircraft flying at an altitude of $3000 \mathrm{~m}$, was used to detect buildings and has a space interval between scanned points of $1 \mathrm{~m}$ and a density of points of about $0.56 / \mathrm{m}^{2}$. Many filtering algorithms have been applied to extract the buildings. However, it is difficult to select appropriate thresholds and filter window sizes for various filtering algorithms. The integration of multispectral imagery and LiDAR data has been considered effective in automatic 3D reconstruction of building and trees [41,42]. Hence, a cloud-free IKONOS multispectral scene by the combination of the 1,2 and 3 bands, acquired on 6 August 2010, was used to extract the information of land use and land cover, which can assist LiDAR data to reconstruct a 3D model of the simulated area. The study area is digitized based on a rectangular grid with a 1-m spatial resolution. The vertical top of the model is set at $2500 \mathrm{~m}$. The timing of the model running is for $24 \mathrm{~h}$, which is decided by the users, depending on the size of the model area, spatial resolution and total number of hours simulated.

Figure 1. The framework of the study methods.

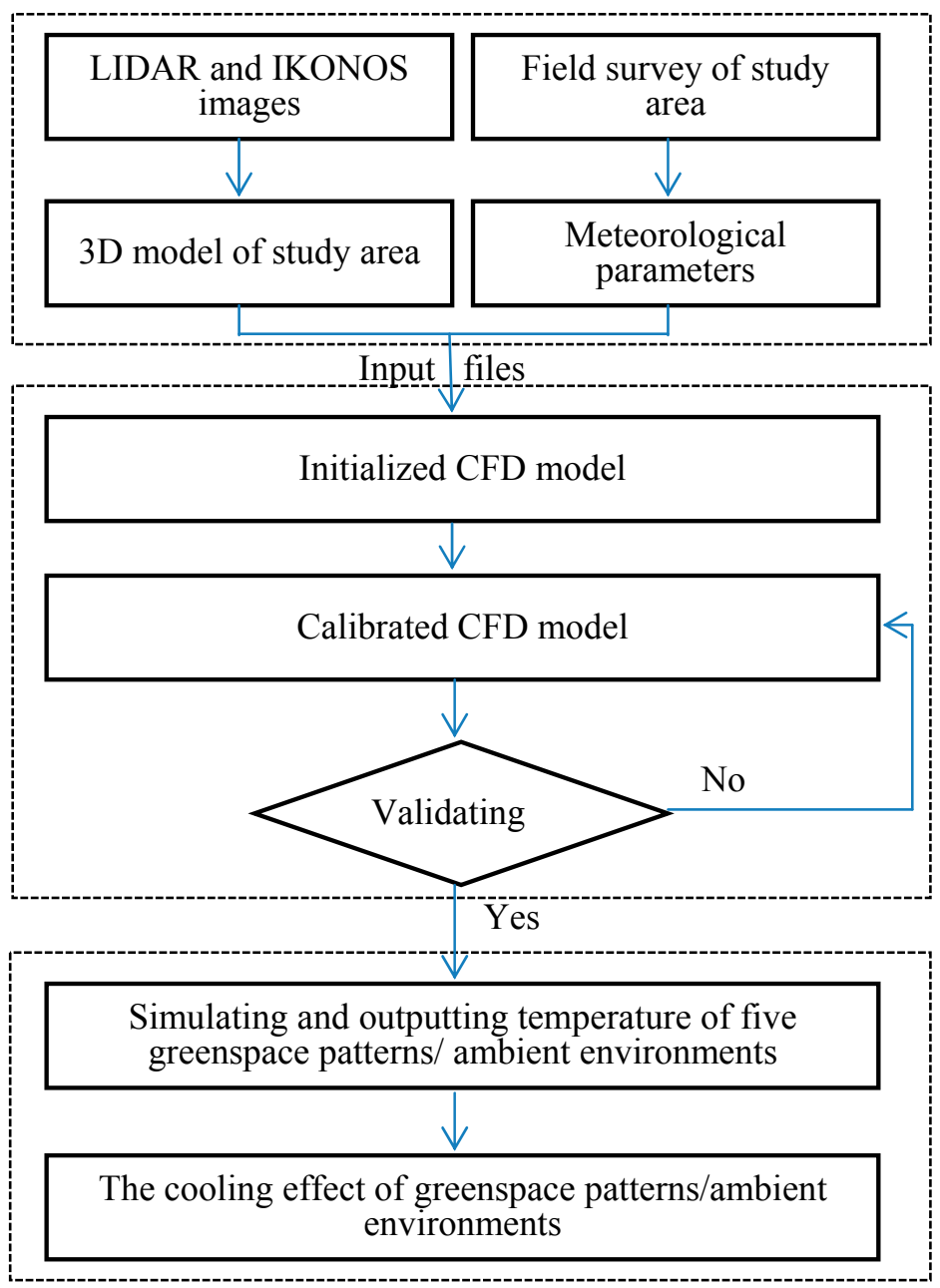


Figure 2. The simulated area (a) and the distribution of tested points (b).
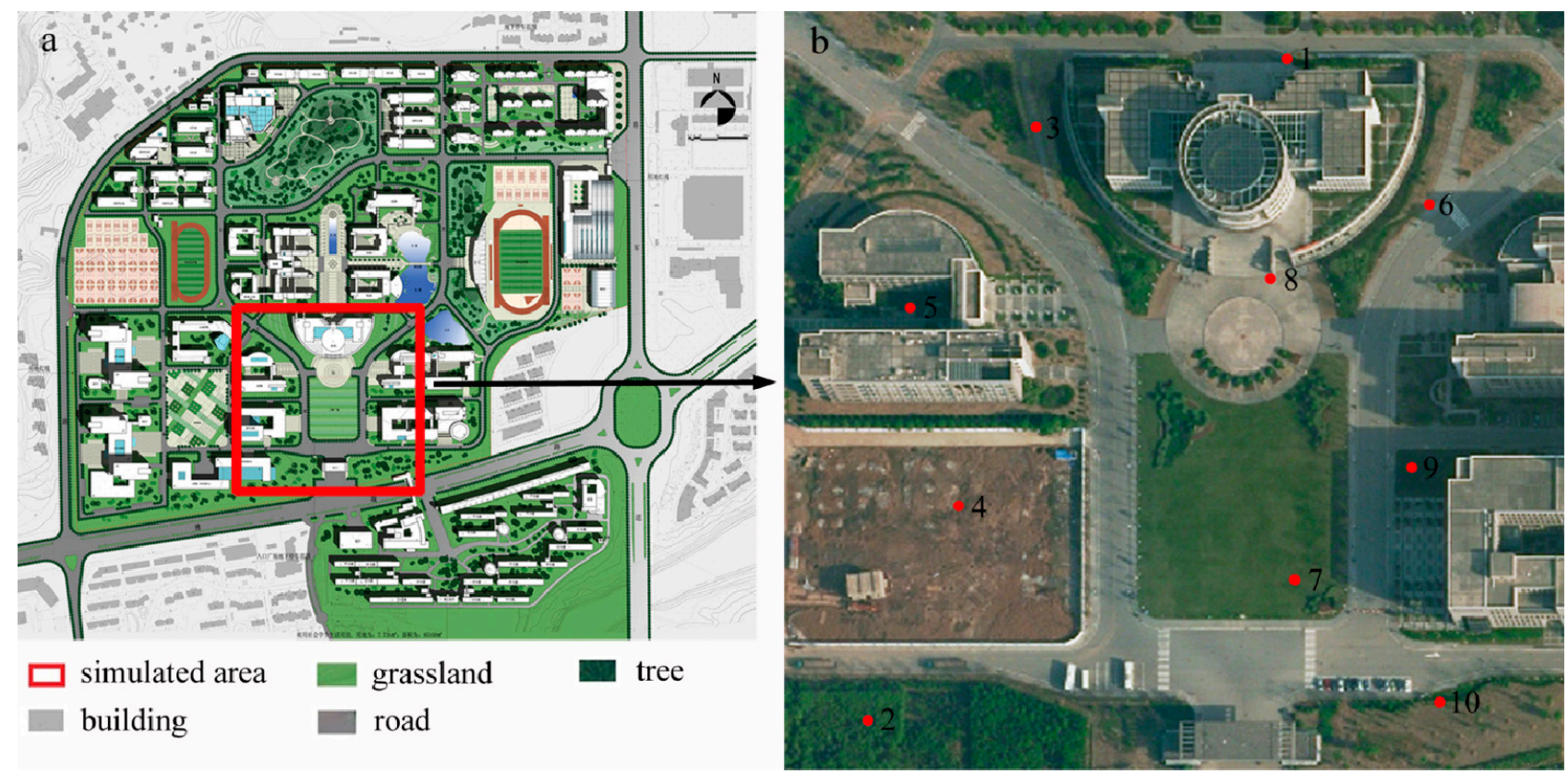

\subsection{Reconstructing 3D Urban Model and Field Survey}

The conventional steps of reconstructing a 3D urban model based on LiDAR data and IKONOS images include filtering (specifically, classifying the LiDAR data into ground points and non-ground points), extraction of building footprints (fusion of LiDAR point and IKONOS image) and reconstruction (generating a 3D model). Firstly, the morphological method of filtering [43] was selected to classify LiDAR points into ground points and non-ground points. Secondly, vegetated points were excluded from the high-rise features by a land cover map derived from IKONOS multispectral bands [44]. As a result, only points that belong to buildings can be selected, and the roof planes of buildings are detected by Hough-transform. Thirdly, the outline of a roof plane is more difficult to determine when the orientation and height of the roof plane can be estimated, and the land and buildings plans are needed to improve the reconstruction accuracy of the 3D building model [45]. Some of the bounds of the roof planes can be reconstructed by intersecting the walls with the detected roof planes, but other bounds are found by the intersection of pairs of adjacent roof planes and the detection of height jump edges in the point clouds. A program has been made to import the 3D model reconstructed by LiDAR and IKONOS images into ENVI-met software, because the 3D model cannot be directly inputted into ENVI-met software.

Thus, the $3 \mathrm{D}$ model of the study area was reconstructed by fusing LiDAR data with IKONOS images (Figure 3a). The simulated results are shown as Figure $3 \mathrm{~b}$ by inputting the 3D model and simulation boundary conditions into calibrated ENVI-met software. Generally, the land surface temperature increases from the tree cover areas to grass cover areas and, again, to the cement road surface. The distribution patterns of land surface temperature accord with the patterns of land cover types. 
Figure 3. The top view of the 3D model (a) and the surface temperature of the simulated area (b).

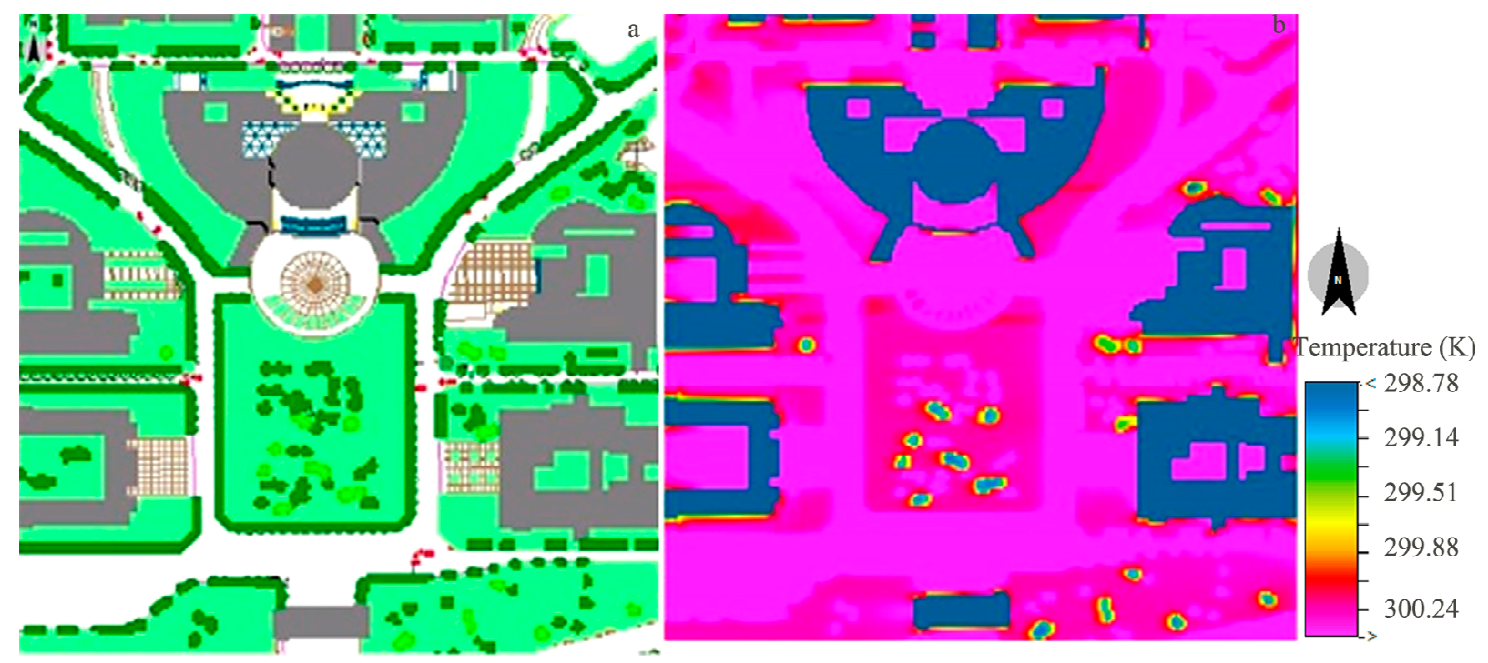

Ten control points (Figure 2b) were identified for field measurement based on the characteristics of the study area with lawn, trees, concrete road and building surfaces and had their average values inputted into the CFD model. Field measurements were performed during a hot and sunny day from 10:00 am on 11 June 2013 to 10:00 am on 12 June 2013. Wind speed, barometric pressure, relative humidity and temperature were measured at about a $1.5 \mathrm{~m}$ height and surface temperature by the Kestrel Meter 4000 Weather Meter.

\subsection{Calibrating CFD Model}

It should be stressed that all mathematical models need validation by an alternative method. The ENVI-met software package was developed at regions with a high latitude and cold climate in the beginning [31], and it is required to validate it for tropical and subtropical regions (e.g., Nanjing, China). Thus, it is important to calibrate the ENVI-met software by field survey, and the comparison between simulated and field data has been done by using the normalized mean square error (NMSE) method to confirm the accuracy of the modelling (Formula 1).

$$
\text { NMSE }=\log _{10} \frac{\sum_{n=1}^{N}|z(n)-z(n)|^{2}}{\sum_{n=1}^{N}|z(n)|^{2}}
$$

$N M S E$ is the normalized mean square error, $N$ the number of samples, $z(n)$ the simulated value of sample $n$ and $z(n)$ the observed value of sample $\mathrm{n}$ by field survey.

The default model parameters in the first iteration of modeling that have been used and simulated are higher than the surface temperature of the field survey (Figure 4). The land surface temperature differences between simulated and field surveyed temperature for 10 control points range from $1.21{ }^{\circ} \mathrm{C}$ to $3.02{ }^{\circ} \mathrm{C}$, and the average temperature difference of 10 control points is $2.07{ }^{\circ} \mathrm{C}$. Point 5 has the largest temperature difference, because it is located in warm areas, due to the obstruction of 
surrounding buildings. The NMSE between the simulated temperature of the first iteration and measured temperature of 10 control points is 2.774 .

Minor changes were made to the configuration of the second iteration, mainly to test the influence of the soil humidity and clouds, because the initial temperature and relative humidity of soils in the middle and deep layers have not been measured by field survey. The relative humidity in the middle and deep layers is set to $70 \%$ (the default value is $60 \%$ ), because it rained just two days before. The other adjusted section is the clouds, whose fractions of low, medium and high clouds were set to 3, 2 and 2, respectively. However, it was sunny and there were few clouds at the simulated time, so that the fractions of low, medium and high clouds were changed to 1, 0, 0, respectively [34]. Simulated results of the second iteration are shown in Figure 4, which presented significant improvements by the comparison with the first iteration. The average temperature difference between the simulated and measured temperature is $0.509{ }^{\circ} \mathrm{C}$. The $N M S E$ between the simulated temperature of the second iteration and measured temperature of 10 control points is 2.139 .

To examine how the 3D model affects the simulation accuracy, the simple 3D model is replaced by the 3D model based on IKONOS images and LiDAR data, which is built by a land use map from the IKONOS images and the estimated height of buildings and trees from GIS data of the study area. Other parameters of the CFD model remain unchanged. The simulated results by the simple 3D model showed that the temperature difference between the simulated and field measured temperatures rises up to $1.19^{\circ} \mathrm{C}$ (the third iteration in Figure 4). Especially for the control Points 3, 5 and 9 around the buildings, the temperature differences are $1.55{ }^{\circ} \mathrm{C}, 1.47{ }^{\circ} \mathrm{C}$ and $1.26{ }^{\circ} \mathrm{C}$, respectively. Therefore, the real 3D model can improve the simulation accuracy of the ENVI-met model. The NMSE between the simulated temperature of the third iteration and the measured temperature of 10 control points is 2.372 .

Figure 4. Temperature differences between the simulated and field measurement.

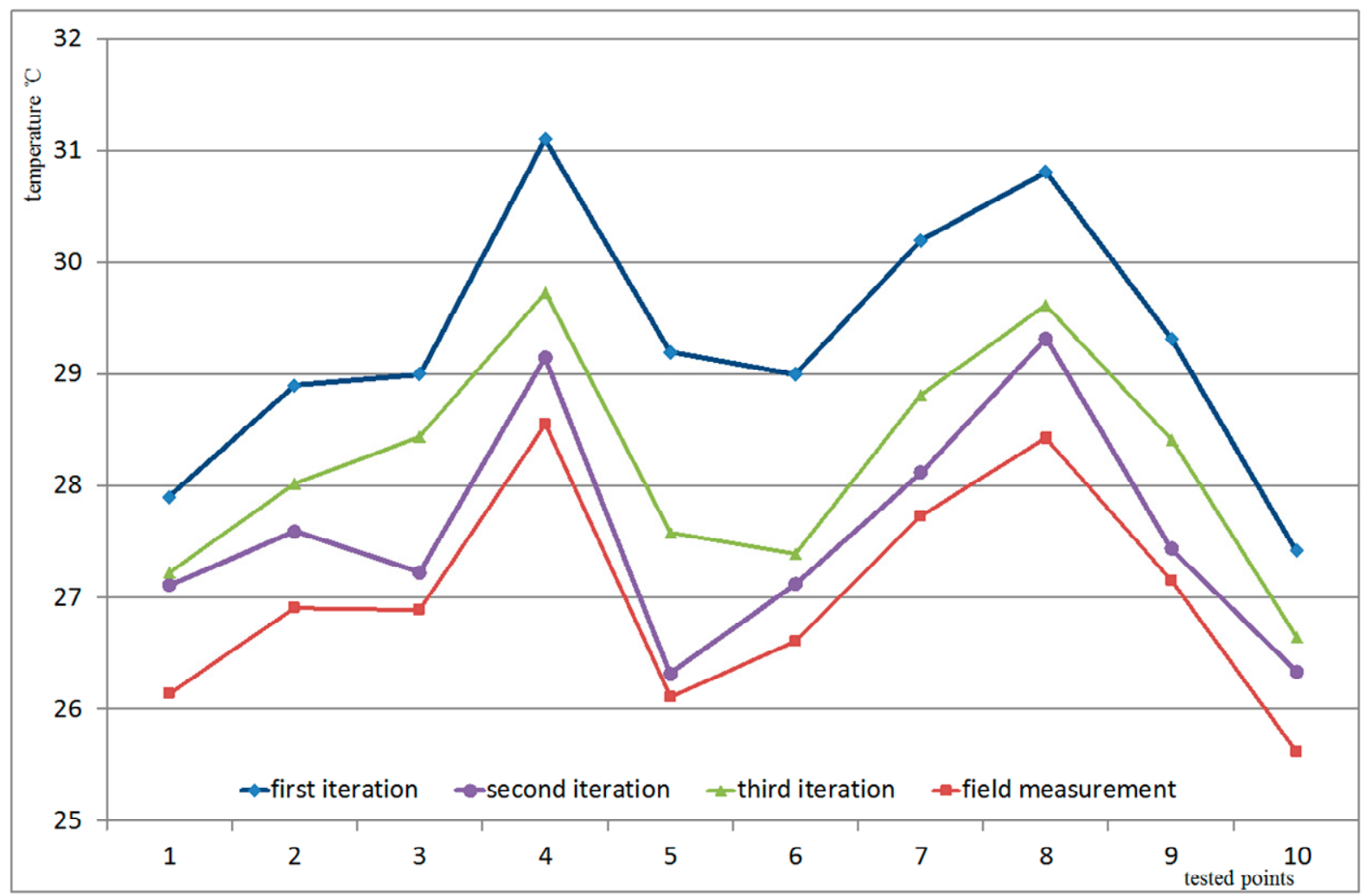




\subsection{Five Models of Greenspace Pattern}

Five spatial patterns of greenspace, such as a dotted pattern, a circular pattern, a radial pattern, a wedge pattern and a zonal pattern, have been discussed very commonly in the fields of urban planning and landscape ecology $[46,47]$ and, thus, are selected to examine the effect of greenspace pattern on surface temperature (Figure 5). Five different factors (Table 1) are simulated to evaluate how the ambient environment impacts the mitigating effect of the greenspace pattern on land surface temperature. For Cases a, b, d and e, there are commonly no buildings or terrain obstructions around the greenspace in the outer suburbs. For Case c, there commonly exist many buildings around the greenspace, changing the direction and strength of air flow around the greenspace, in the central area inside the urban environment. The modelling settings in greenspace patterns accord with those of the modelling in the Jiangning study areas on the 12 June 2013.

Figure 5. Five spatial patterns of greenspace: (a) dotted pattern; (b) circular pattern; (c) radial pattern; (d) wedge pattern and (e) zonal pattern.
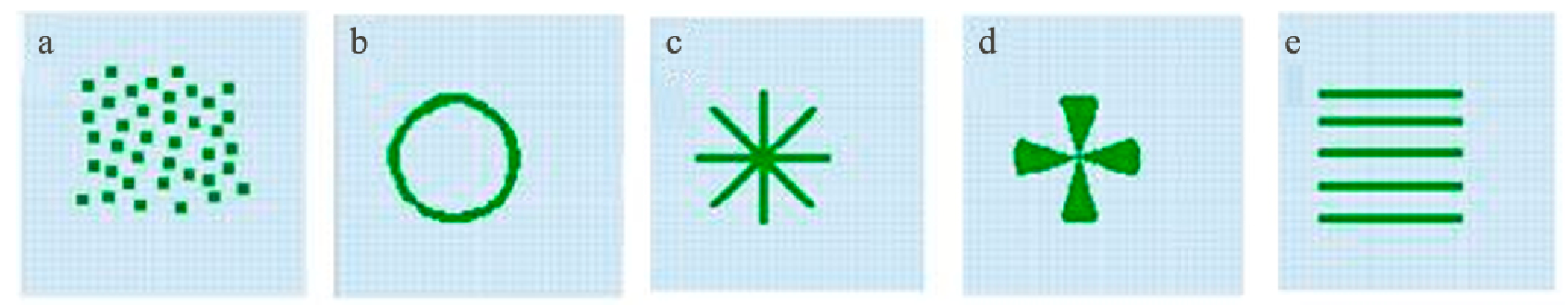

Table 1. Five factors of ambient environments.

\begin{tabular}{ccccccc}
\hline Case & $\begin{array}{c}\text { Underlying } \\
\text { type }\end{array}$ & $\begin{array}{c}\text { Vegetation } \\
\text { type }\end{array}$ & $\begin{array}{c}\text { Vegetation } \\
\text { Height } \mathbf{( m )}\end{array}$ & $\begin{array}{c}\text { Vegetation } \\
\left.\text { area } \mathbf{( k m}^{\mathbf{2}}\right)\end{array}$ & $\begin{array}{c}\text { Total area } \\
\left.\mathbf{( k m}^{\mathbf{2}}\right)\end{array}$ & $\begin{array}{c}\text { Obstruction } \\
\text { situation }\end{array}$ \\
\hline $\mathrm{a}$ & soil & tree & 5 & 0.08 & 0.64 & no \\
$\mathrm{b}$ & soil & grass & 0.2 & 0.04 & 0.64 & no \\
$\mathrm{c}$ & soil & tree & 5 & 0.04 & 0.64 & no \\
$\mathrm{d}$ & soil & tree & 5 & 0.04 & 0.64 & buildings \\
$\mathrm{e}$ & grass & tree & 5 & 0.04 & 0.64 & no \\
\hline
\end{tabular}

\section{Results}

\subsection{Simulated Temperature of Five Types of Greenspace Patterns}

Case $\mathrm{d}$ (Table 1) is selected to simulate and analyze the land surface temperature of different greenspace pattern characteristics according to the average temperature and statistics curves of simulated temperature. For the dotted-pattern greenspace, the vegetation is uniformly and dispersedly located in the given region, so that the frequency of the internal heat exchange between vegetation is very low. According to the percentage of low (lower than $299.0 \mathrm{~K}$ ), high (higher than $300.0 \mathrm{~K}$ ) and moderate temperature areas (from $299.0 \mathrm{~K}-300.0 \mathrm{~K}$ ), the dotted pattern without low temperature areas presented a higher percentage of high temperature area and had the highest average simulated temperature (Table 2). The lower and higher temperature mainly occurs on the inner greenspace and outside greenspace. The dotted-pattern greenspace maybe improve the local climate, but is ineffective 
at regulating the climate of a large area (Figure 6a). The circular pattern presented a higher percentage of high temperature area and a much higher simulated temperature. The low-temperature areas are mainly located at the areas between the greenspace and its downwind direction (Figure 6b).

However, the temperature patterns of the radial and wedge patterns have certain similarities (Figure $6 \mathrm{c}, \mathrm{d}$ ). The wedge and radial patterns presented a higher percentage of low and moderate temperature area and therefore, a lower overall temperature of the simulated area. Additionally, the two patterns showed a relatively homogeneous temperature distribution in their internal greenspace and also formed an extremely low-temperature area along the downwind direction. The zonal pattern had the lowest percentage of low and high temperature area and average temperature. The cooling effect is obvious around the corridors between green belts (Figure 6e).

Figure 6. Simulated surface temperature by five patterns: (a) dotted pattern; (b) circular pattern; (c) radial pattern; (d) wedge pattern; (e) zonal pattern.
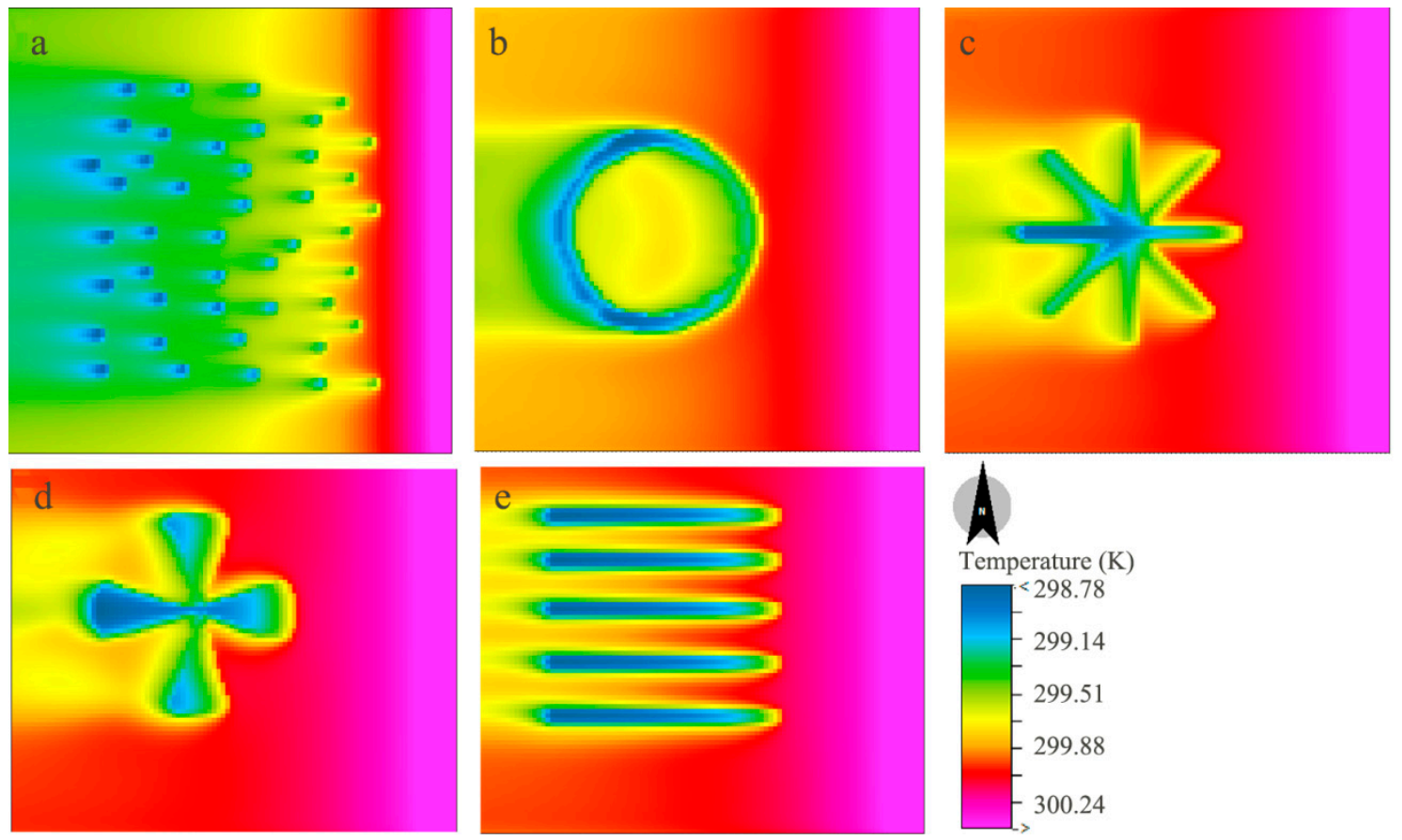

Table 2. Average temperature and temperature distribution characteristics.

\begin{tabular}{ccccc}
\hline Pattern & $\begin{array}{c}\text { Average } \\
\text { temperature } \\
(\mathbf{K})\end{array}$ & $\begin{array}{c}\text { Low } \\
\text { temperature } \\
\text { area (\%) }\end{array}$ & $\begin{array}{c}\text { High } \\
\text { temperature } \\
\text { area (\%) }\end{array}$ & $\begin{array}{c}\text { Median } \\
\text { temperature } \\
\text { area (\%) }\end{array}$ \\
\hline Dotted pattern & 299.991 & 0 & 26.45 & 73.55 \\
Radial pattern & 299.509 & 2.79 & 21.98 & 75.23 \\
Circular pattern & 299.740 & 0.96 & 25.25 & 73.79 \\
Zonal pattern & 298.768 & 6.09 & 25.55 & 68.36 \\
Wedge pattern & 299.491 & 3.38 & 17.86 & 78.76 \\
\hline
\end{tabular}

\subsection{Impact of Ambient Environment on Mitigating Effect of Greenspace Pattern}

Four factors, including greenspace type, greenspace area, underlying type and topology (terrain), have been used to analyze the influence on UHI. Firstly, the effect of the greenspace type on 
temperature is analyzed by comparing Case $b$ with Case $\mathrm{d}$. The simulated average temperature of Case $\mathrm{b}$ for all greenspace patterns rises and is $0.3{ }^{\circ} \mathrm{C}$ for the dotted pattern, $0.82{ }^{\circ} \mathrm{C}$ for the radial pattern, $1.08{ }^{\circ} \mathrm{C}$ for the zonal pattern, $0.5^{\circ} \mathrm{C}$ for the circular pattern and $0.84{ }^{\circ} \mathrm{C}$ for the wedge pattern, respectively. Secondly, Cases $\mathrm{c}$ and $\mathrm{d}$ are used to compare how the underlying surface affects the temperature distribution. The simulated temperature of Case $\mathrm{c}$ declines $1.32{ }^{\circ} \mathrm{C}, 0.93{ }^{\circ} \mathrm{C}, 0.95{ }^{\circ} \mathrm{C}$, $1.01{ }^{\circ} \mathrm{C}$ and $0.76{ }^{\circ} \mathrm{C}$ for dotted, radial, zonal, circular and wedge patterns, respectively. Thus, the cooling effect of the dotted pattern has been greatly improved when the underlying surface is grassland and trees. Thirdly, with the comparison of Case a with Case d, to analyze the effect of greenspace area, the simulated surface temperature of Case a declines and is $0.35^{\circ} \mathrm{C}$ for the dotted pattern, $0.19{ }^{\circ} \mathrm{C}$ for the radial pattern, $0.15{ }^{\circ} \mathrm{C}$ for the circular pattern, $0.42{ }^{\circ} \mathrm{C}$ for the zonal pattern and $0.13{ }^{\circ} \mathrm{C}$ for the wedge pattern, respectively. Increasing the greenspace area will play a greater role in mitigating the effect on UHI for the zonal pattern. However, the worst cooling effect is for the circular pattern, because it is more enclosed by trees and it is very difficult to form air convection with the outside air. Lastly, a comparative analysis is made between Cases c and e to reveal which kind of greenspace pattern has a better cooling effect for inner cities where more buildings exist. The average simulated temperature of Case e rises $0.72{ }^{\circ} \mathrm{C}, 0.92{ }^{\circ} \mathrm{C}, 1.67{ }^{\circ} \mathrm{C}, 1.42{ }^{\circ} \mathrm{C}$ and $0.86{ }^{\circ} \mathrm{C}$ for the dotted, radial, zonal, circular and wedge patterns, respectively. For the inner urban area, the dotted and wedge patterns play a greater role in mitigating UHI.

\section{Discussions}

\subsection{The Importance of Model Calibration}

The simulated results of the first and second iteration clearly showed that the calibration of default parameters in the ENVI-met model can improve modelling accuracy. Compared with previous research results $[10,48,49]$, the model fit for surface temperature is acceptable and can be validated for the comparison of the impacts of five greenspace patterns on land surface temperature. Thus, we inferred that a well-calibrated model always functions well and may obtain effective results even under the conditions of changing simulated scenarios for a given study objective. Moreover, the input parameters of the ENVI-met model were based on field survey in the study area and cannot be used directly for other study areas, due to the differences in parameters, such as soil humidity, air temperature and simulation time, according to the climate and weather characteristics. Many researchers in this field of research have considered 3D real areas in the CFD model [50], but 3D models have commonly been constructed based on the GIS data and land cover map. The simulated results in the third iteration showed that the accuracy of the 3D model based on LiDAR data has also improved the CFD modelling accuracy in the paper.

However, there are still some limitations, such as the complexity and plethora of urban details, the high computational cost of simulations and the accuracy of the 3D model in the current ENVI-met model version, including the calibrated model in the paper. Researchers have proposed that the integration [51] of micro-scale, median-scale models and remote sensing technology with the CFD model should be regarded as the development trend for improving the effectiveness and accuracy of the modelling process. In the paper, the focus of the modelling is on the theoretical patterns of urban 
greenspace impacts on UHI in the local scale, and not the patterns of real land patches, such as land use/land cover patches derived from the remote sensing images. The five types of theoretical greenspace patterns have been widely studied and planned in the field of urban planning and landscape ecology and must be tested with the real study area at different scales, such as city, urban sub-areas and urban function areas (e.g., a residential, industrial zone), according to the special environment parameters.

\subsection{The Cooling Effect of Greenspace Pattern on UHI}

Different spatial arrangements of greenspace and the means and amount of heat exchange among soil-vegetation-air generate different effects for mitigating UHI. However, there is not a very huge difference in the average surface temperature across the five patterns. The biggest average surface temperature difference occurred between the zonal pattern and dotted pattern and is $1.23{ }^{\circ} \mathrm{C}$; the temperature difference between the dotted pattern and circular patterns is $0.25{ }^{\circ} \mathrm{C}$, and the difference between the wedge pattern and radial pattern is not obvious. This may be a result of the simple ambient environment (e.g., flat terrain, simple land cover types) and the simulated area of the study area.

The zonal pattern always shows the lowest average temperature, because the trees between greenbelts not only intercept incoming solar radiation, but also reflect short-wave radiation from their surroundings and long-wave radiation from the land surface and the sky. In some cases, there is significant sensible heat exchanges between the urban warm air and the cooler leaves [52]. It is difficult to form a strong air convection with the dotted pattern of greenspace, so that the simulated surface temperature becomes the highest among the five patterns. The radial pattern and wedge pattern have many similarities in the temperature distribution characteristics and can form a "cold source" in the urban environment, because they can introduce fresh air for the urban environment and also play an important role in improving the spatial scope of the urban greenspace cooling effect. The two types of patterns, especially the wedge pattern, are more sustainable greenspace models. Besides the obvious cooling effect, they also have good accessibility for urban residents to rest, for recreation and for education. The wedge-pattern greenspace belt is best parallel to the direction of dominant wind in the city and having a width greater than 20 meters. The greenspace should use native and leafy trees and also be integrated with the river within the city, which has the function of a greenspace. These are two kinds of ideal greenspace patterns to mitigate UHI. The circular pattern is relatively closed, and it is difficult to form a heat exchange between trees and air, so the average surface temperature is higher.

\subsection{The Influences of Ambient Environment on the Cooling Effect of the Greenspace Pattern}

The influences of different factors on the greenspace pattern are multiple. The microclimate in an urban space is influenced by the adjacent buildings and landscape elements and their complex interactions [53]. Complicated geometry results in higher average surface temperature for all patterns, with an increase of $1.11^{\circ} \mathrm{C}$ of the average temperature of the five patterns. However, the zonal pattern is much more sensitive to geometry and has the highest average surface temperature. On the contrary, the geometry has little effect on the dotted pattern, so that it shows the lowest average temperature. Radial, wedge and circular patterns have higher surface temperature under complicated geometry. If the area of greenspace increases to $50 \%$ of its area, the average surface temperature of the five 
greenspace patterns decreases $0.248^{\circ} \mathrm{C}$. Therefore, the greenspace area has the least effect among all ambient environment factors, but for the zonal pattern, it shows an obvious cooling effect when the greenspace area increases. If the type of greenspace changes from tree to grass, the average surface temperature of the five patterns increases $0.708{ }^{\circ} \mathrm{C}$, because the lawn decreases temperatures mainly through ground evapotranspiration [54]. This type of greenspace has little impact on the dotted pattern, because dotted trees over a wider area cannot form a strong air convection and a cooler local microclimate. However, the type of greenspace exercises a great influence on the zonal and circular patterns, because the trees in the two patterns can generate very strong local airflow, shade and evaporative cooling [54]. If the land surface is composed of grassland, soil and trees, the average surface temperature of the five space patterns decreases $0.994{ }^{\circ} \mathrm{C}$. However, the cooling effect of the dotted pattern has been greatly improved, so that the mixed greenspace types, such as the combination of grass and trees, is more suitable for the dotted pattern.

\section{Conclusions}

It is necessary to calibrate ENVI-met software with field surveys to confirm its suitability. By adjusting the default parameters and soil humidity of the ENVI-met model, the average simulation errors decrease $2.07{ }^{\circ} \mathrm{C}$ and $0.509{ }^{\circ} \mathrm{C}$, respectively. The 3D model built by IKONOA images and LiDAR data in this paper also has improved the modelling accuracy and made the modelling error reduce by $1.19^{\circ} \mathrm{C}$ compared with the simulation results of the $3 \mathrm{D}$ model based on a land cover map.

This paper reports the cooling effects of different theoretical greenspace patterns on land surface temperature based on the calibrated CFD model. Firstly, the zonal pattern always shows the lowest average temperature, and it is difficult for the dotted pattern of greenspace to form strong air convection, thus resulting in the highest temperature. The radial pattern and wedge pattern have many similarities in the temperature distribution characteristics and can form a "cold source" in the urban environment. The circular pattern is relatively closed, and the heat exchange between trees and air is difficult to form, so the average surface temperature is higher. Secondly, complicated geometry results in higher average surface temperature for all patterns with an increase of $1.11^{\circ} \mathrm{C}$, but has much more effect on the zonal pattern and little effect on the dotted pattern. The greenspace area has the least effect among all ambient environment factors, with the exception of the zonal pattern.

The relationship between greenspace patterns and land surface temperature is useful for planners and decision-makers to guide the sustainable design of urban greenspace. The types of patterns, the radial patter and especially the wedge pattern, are more sustainable greenspace models. Besides the obvious cooling effect, they also have good accessibility for urban residents to rest, for recreation and for education. For ambient environments, the building or terrain obstacles have the hugest influence on mitigating the UHI, and the greenspace should use native and leafy trees and also be integrated with the river within the city.

\section{Acknowledgments}

We would like to thank Michigan State University and Guo Chen for helpful comments and edits. This work was supported by the National Natural Science Foundation of China (No. 41171429; No. 41271538) and the Program for Frontier Research Issues in Chinese Academy Science 
(No. NIGLAS2012135022). We sincerely thank the editor and three anonymous reviewers for their constructive comments and suggestions.

\section{Author Contributions}

The authors shared equally in the intellectual development and writing of the paper. Weizhong Su and Yingbao Yang developed the original idea and contributed to the research design for the study. Yong Zhang and Gaobin Ye were responsible for data collecting. All authors drafted and approved the final manuscript.

\section{Conflicts of Interest}

The authors declare that they have no conflict of interest for this work.

\section{References}

1. Landsberg, H.E. The Urban Climate; Academic Press: New York, NY, USA, 1981.

2. Sarrat, C.; Lemonsu, A.; Masson, V.; Guedalia, D. Impact of urban heat island on regional atmospheric pollution. Atmos. Environ. 2006, 40, 1743-1758.

3. Bowler, D.E.; Buyung-Ali, L.; Knight, T.M.; Pullin, A.S. Urban greening to cool towns and cities: A systematic review of the empirical evidence. Landsc. Urban Plan. 2010, 97, 147-155.

4. Coutts, A.M.; Daly, E.; Beringer, J.; Tapper, N.J. Assessing practical measures to reduce urban heat: Green and cool roofs. Build. Environ. 2013, 70, 266-276.

5. Gill, S.; Handley, J.; Ennos, A.; Pauleit, S. Adapting cities for climate change: The role of the green infrastructure. Built Environ. 2007, 3, 115-133.

6. Gill, S.E.; Handley, J.F.; Ennos, A.R.; Pauleit, S.; Theuray, N.; Lindley, S.J. Characterising the urban environment of UK cities and towns: A template for landscape planning. Landsc. Urban Plan. 2008, 87, 210-222.

7. Chang, C.-R.; Li, M.-H.; Chang, S.-D. A preliminary study on the local cool-island intensity of Taipei city parks. Landsc. Urban Plan. 2007, 80, 386-395.

8. Zoulia, I.; Santamouris, M.; Dimoudi, A. Monitoring the effect of urban green areas on the heat island in Athens. Environ. Monit. Assess. 2009, 156, 275-292.

9. Nyuk, H.W.; Puay, Y.T.; Yu, C. Study of thermal performance of extensive rooftop greenery systems in the tropical climate. Build. Environ. 2007, 42, $25-54$.

10. Skelhorn, C.; Lindley, S.; Levermore, G. The impact of vegetation types on air and surface temperatures in a temperate city: A fine scale assessment in Manchester, UK. Landsc. Urban Plan. 2014, 121, 129-140.

11. Yilmaz, S.; Toy, S.; Irmak, M.A.; Yilmaz, H. Determination of climatic differences in three different land uses in the city of Erzurum, Turkey. Build. Environ. 2007, 42, 1604-1612.

12. Lehmann, I.; Mathey, J.; Rößler, S.; Bräuer, A.; Goldberg, V. Urban vegetation structure types as a methodological approach for identifying ecosystem services-Application to the analysis of micro-climatic effects. Ecol. Indicat. 2014, 42, 58-72. 
13. Li, X.; Zhou, W.; Ouyang, Z.; Xu, W.; Zheng, H. Spatial pattern of greenspace affects land surface temperature: Evidence from the heavily urbanized Beijing metropolitan area, China. Landsc. Ecol. 2012, 27, 887-898.

14. Weng, Q.; Lu, D.; Schubring, J. Estimation of land surface temperature-vegetation abundance relationship for urban heat island studies. Rem. Sens. Environ. 2004, 89, 467-483.

15. Zhou, W.; Huang, G.; Cadenasso, M.L. Does spatial configuration matter? Understanding the effects of land cover pattern on land surface temperature in urban landscapes. Landsc. Urban Plan. 2011, 102, 54-63.

16. Su, W.; Yang, G.; Chen, S.; Yang, Y. Measuring the Pattern of High Temperature Areas in Urban Greenery of Nanjing City, China. Int. J. Environ. Res. Publ. Health. 2012, 9, 2922-2935.

17. Takebayashi, H.; Moriyama, M. Surface heat budget on green roof and high reflection roof for mitigation of urban heat island. Build. Environ. 2007, 42, 2971-2979.

18. Wong, M.S.; Nichol, J.E. Spatial variability of frontal area index and its relationship with urban heat island intensity. Int. J. Rem. Sens. 2012, 34, 885-896.

19. Su, W.; Gu, C.; Yang, G. Assessing the impact of land use/land cover on urban heat island pattern in Nanjing City, China. J. Urban Plan. Dev. 2010, 136, 365-372.

20. Mirzaei, P.A.; Haghighat, F. Approaches to study Urban Heat Island-Abilities and limitations. Build. Environ. 2010, 45, 2192-2201.

21. Lee, S.-H.; Lee, K.-S.; Jin, W.-C.; Song, H.-K. Effect of an urban park on air temperature differences in a central business district area. Landsc. Ecol. Eng. 2009, 5, 183-191.

22. Wong, N.H.; Yu, C. Study of green areas and urban heat island in a tropical city. Habitat Int. 2005, 29, 547-558.

23. Liu, L.; Zhang, Y. Urban heat island analysis using the Landsat TM data and ASTER data: A case study in Hong Kong. Rem. Sens. 2011, 3, 1535-1552.

24. Asawa, T.; Hoyano, A.; Nakaohkubo, K. Thermal design tool for outdoor spaces based on heat balance simulation using a 3D-CAD system. Build. Environ. 2008, 43, 2112-2123.

25. Ferreira, R.A.C.; Silva Zacarin, E.C.M.; Malaspina, O.; Bueno, O.C.; Tomotake, M.E.M.; Pereira, A.M. Cellular responses in the Malpighian tubules of Scaptotrigona postica (Latreille, 1807) exposed to low doses of fipronil and boric acid. Micron 2013, 46, 57-65.

26. Ashie, Y.; Kono, T. Urban-scale CFD analysis in support of a climate-sensitive design for the Tokyo Bay area. Int. J. Climatol. 2011, 31, 174-188.

27. Melnyk, L.; Bernard, C.; Morgan, J. Detection of toxicants on building surfaces following a chemical attack. In Proceeding of the ACS Meeting, New York, NY, USA, 7-11 September 2003.

28. Takahashi, K.; Yoshida, H.; Tanaka, Y.; Aotake, N.; Wang, F. Measurement of thermal environment in Kyoto city and its prediction by CFD simulation. Energ. Build. 2004, 36, 771-779.

29. Weng, Q. Thermal infrared remote sensing for urban climate and environmental studies: Methods, applications, and trends. ISPRS J. Photogramm. Rem. Sens. 2009, 64, 335-344.

30. Hedger, R.D.; Olsen, N.R.; Malthus, T.J.; Atkinson, P.M. Coupling remote sensing with computational fluid dynamics modelling to estimate lake chlorophyll-a concentration. Rem. Sens. Environ. 2002, 79, 116-122.

31. Bruse, M. ENVI-met bulletin board. Available online: http://www.envi-met.com (accessed on 17 March 2009). 
32. Bruse, M.; Fleer, H. Simulating surface-plant-air interactions inside urban environents with a three dimensional numerical model. Environ. Model. Software 1998, 13, 373-384.

33. Huttner, S.; Bruse, M.; Dostal, P. Using ENVI-met to simulate the impact of global warming on the microclimate in Central European Cities. In 5th Japanese-German Meeting on Urban Climatology; Meteorological Institute, Albert-Ludwigs-University: Freiburg, Germangy, 2008; pp. 307-312.

34. Maggiotto, G.; Buccolieri, R.; Santo, M.A.; Leo, L.S.; di Sabatino, S. Validation of temperature-perturbation and CFD-based modelling for the prediction of the thermal urban environment: The Lecce (IT) case study. Environ. Model. Softw. 2014, 60, 69-83.

35. Cheng, L.; Gong, J.; Li, M.; Liu, Y. 3D Building Model Reconstruction from Multi-view Aerial Imagery and Lidar Data. Photogramm. Eng. Rem. Sens. 2011, 77, 125-139.

36. Satari, M.; Samadzadegan, F.; Azizi, A.; Maas, H.G. A Multi-Resolution Hybrid Approach for Building Model Reconstruction from Lidar Data. Photogramm. Rec. 2012, 27, 330-359.

37. Chen, S.; Jim, C.Y. Quantitative assessment of the treescape and cityscape of Nanjing, China. Landsc. Ecol. 2003, 18, 395-412.

38. Awrangjeb, M.; Zhang, C.; Fraser, C.S. Automatic extraction of building roofs using LiDAR data and multispectral imagery. ISPRS J. Photogramm. Rem. Sens. 2013, 83, 1-18.

39. Cheng, L.; Tong, L.; Chen, Y.; Zhang, W.; Shan, J.; Liu, Y.; Li, M. Integration of LiDAR data and optical multi-view images for 3D reconstruction of building roofs. Optic Laser Eng. 2013, 51, 493-502.

40. Uzar, M.; Yastikli, N. Automatic building extraction using LiDAR and aerial photographs. Bol. Ciênc. Geod. 2013, 19, 153-171.

41. Chen, L.; Zhao, S.; Han, W.; Li, Y. Building detection in an urban area using lidar data and QuickBird imagery. Int. J. Rem. Sens. 2012, 33, 5135-5148.

42. Kim, J.; Muller, J.-P. Tree and building detection in dense urban environments using automated processing of IKONOS image and LiDAR data. Int. J. Rem. Sens. 2011, 32, 2245-2273.

43. Chen, Q.; Gong, P.; Baldocchi, D.; Xie, G. Filtering Airborne Laser Scanning Data with Morphological Methods. Photogramm. Eng. Rem. Sens. 2007, 73, 175-185.

44. Sohn, G.; Dowman, I. Data fusion of high-resolution satellite imagery and LiDAR data for automatic building extraction. ISPRS J. Photogramm. Rem. Sens. 2007, 62, 43-63.

45. Vosselman, G.; Dijkman, S. 3D building model reconstruction from point clouds and ground plans. Int. Arch. Photogramm. Rem. Sens. Spat. Inform. Sci. 2001, 34, 37-44.

46. Turner, M.G. Spatial and temporal analysis of landscape patterns. Landsc. Ecol. 1990, 4, 21-30.

47. Poudyal, N.C.; Hodges, D.G.; Tonn, B.; Cho, S.H. Valuing diversity and spatial pattern of open space plots in urban neighborhoods. For. Pol. Econ. 2009, 11, 194-201.

48. Emmanuel, R.; Fernando, H. Urban heat islands in humid and arid climates: Role of urban form and thermal properties in Colombo, Sri Lanka and Phoenix, USA. Clim. Res. 2007, 34, 241-251.

49. Wong, N.H.; Kardinal Jusuf, S.; Aung La Win, A.; Kyaw Thu, H.; Syatia Negara, T.; Xuchao, W. Environmental study of the impact of greenery in an institutional campus in the tropics. Build. Environ. 2007, 42, 2949-2970.

50. Murakami, S. Environmental design of outdoor climate based on CFD. Fluid Dynam. Res. 2006, $38,108-126$. 
51. Li, K.; Yu, Z. Comparative and combinative study of urban heat island in Wuhan City with remote sensing and CFD simulation. Sensors 2008, 8, 6692-6703.

52. Bonan, G.B. The microclimates of a suburban Colorado (USA) landscape and implications for planning and design. Landsc. Urban Plan. 2000, 49, 97-114.

53. Shashua-Bar, L.; Pearlmutter, D.; Erell, E. The cooling efficiency of urban landscape strategies in a hot dry climate. Landsc. Urban Plan. 2009, 92, 179-186.

54. Erell, E.; Williamson, T. Simulating air temperature in an urban street canyon in all weather conditions using measured data at a reference meteorological station. Int. J. Climatol. 2006, 26, 1671-1694.

(C) 2014 by the authors; licensee MDPI, Basel, Switzerland. This article is an open access article distributed under the terms and conditions of the Creative Commons Attribution license (http://creativecommons.org/licenses/by/4.0/). 